\title{
On the telescopes in the paintings of Jan Brueghel the Elder
}

\author{
Paolo Molaro and Pierluigi Selvelli \\ INAF-Osservatorio Astronomico di Trieste, \\ Via G.B. Tiepolo 11, 34143 Trieste, Italy \\ email: molaro@inaf.oats.it selvelli@inaf.oats.it
}

\begin{abstract}
Several astronomical instruments including early spyglasses are depicted in at least five paintings that Jan Brueghel the Elder completed between 1608 and 1625. This rather unique circumstance is due to the fact that Jan Brueghel was court painter of Archduke Albert VII of Habsburg, whose love for art and science, he celebrated in his paintings. An optical tube that appears in the Extensive Landscape with View of the Castle of Mariemont, dated 1608-1612 represents the first painting of a telescope whatsoever. Some documents are collected showing that Albert VII could have obtained very early spyglasses directly from Lipperhey or Sacharias Janssen, who are two possible inventors of the telescope. Thus the painting could reproduce one of the first telescopes ever made by mankind. Two more instruments appear prominently in two Allegories of Sight made in the years 1617 and 1618. These are precious instruments made possibly in silver, composed by several draw-tubes, which look much more sophisticated than other instruments of same epoch. Rather surprisingly, the structure and, in particular the eyepiece, suggest that they may represent the first examples of Keplerian telescopes about two decades before they replaced the Dutch mounting.
\end{abstract}

Keywords. Invention of telescope, keplerian telescopes, Jan Brueghel paintings, Galileo Galilei, International Year of Astronomy.

\section{Introduction}

Spyglasses and other astronomical instruments are present in five paintings, one Landscape and four Allegories, that Jan Brueghel the Elder (1568-1625) made in the years between 1610 and 1625, with the occasional contribution of P. P. Rubens.

The paintings were drawn while the artist was appointed as a court painter of Archduke Albert VII of Habsburg (1559-1621), Spanish Governor of the catholic part of Netherlands, and his spouse Archduchess Isabella Clara Eugenia, infanta of Spain and daughter of Felipe II. This rather unique circumstance is due the genuine scientific interests of his protector, Archduke Albert VII . All five paintings can be considered as a high quality, realistic pictures and are rich of details. This allows a detailed exam of the instruments therein depicted, as well as an investigation on their nature. A first report of this analysis has been given in Selvelli and Molaro (2009).

\section{The first painting of a spyglass}

The painting Extensive Landscape with View of the Castle of Mariemont is conserved at the Virginia Museum of Fine Arts in Richmond, VA, USA. The Mariemont Castle located near Bruxelles and reproduced in the painting was under reform for several years, and a study of the development of the building, by comparison with paintings of ascertained dates, has allowed to estimate that the date of the painting completion was in the years 1608 - 1611. In the central and left part of the painting, shown in Fig. 1, 
one can see the Archduke Albert VII looking through a spyglass. The instrument has a cylindrical shape and appears as metallic, probably made of tin, with two gilded rings on both sides. By comparison with figures and objects, one can estimate that its length is about $40-46 \mathrm{~cm}$ and its diameter of about $5 \mathrm{~cm}$.

To our knowledge, this painting represents the most ancient reproduction of a spyglass. Moreover, several documentation pieces allow us to link this early instrument with one made by the unknown inventor of the telescope. One evidence comes from Daniello Antonini, a noble from Udine and friend of Galileo that was serving in the Archduke army in Brussels. In September 1611 Antonini wrote a letter to his former master Galileo telling that the Archduke had some spyglasses, although of lower quality as compared to those owned by Galileo obtained from the inventor. Literarily: "Ho veduti de' piu' esquisiti occhiali che si fabrichino in queste parti. N' ho veduti di quegli del proprio primo inventore, dati poi a questo Serenissimo, ma son tutti dozinali'. Already in 1646 Maria Schyrlaeus de Rheita in its Oculus Enoch et Eliae at p. 337 wrote that the Marqués Ambrogio Spinola, Commander of the Spanish Army in the Flanders, bought a spyglass in The Hague near the end of 1608, probably made by Lipperhey, and offered it to Archduke Albert. Spinola was in The Hague in that period, as a representant of the Spanish Governor, for peace negotiations with the Staatsholder of the seven provinces Maurice of Nassau, which was actually signed in April 1609.

Independent information comes from Guido Bentivoglio the Papal nuncio at the court of Albert VII that was quite close to the very religious Archduke and present when Spinola came back from the Hague after having witnessed to the first public demonstration of a telescope. Bentivoglio on the 2nd of April 1609 in a letter to Cardinal Scipione Borghese nephew of Paul V and papal secretary wrote: "When the marquis Spinola returned from Holland [...] the Archduke and the Marquis himself were most desirous to obtain such an instrument, and indeed it came about that one came into their hands, although not of such perfection as the one owned by Count Maurice". Concerning the manufacturer, it could be either Lipperhey or Janssen, both considered as "fathers" of the telescope. A case in favour of the latter comes from Pierre Borel, who in the De Vero Telescopii Inventore of the 1656 quotes the son of Sacharias Janssen declaration, given in 1655, to the Middelburg City Council in an investigation of the origin of the telescope. The declaration sounds: "Our artisan [Sacharias Janssen] first made tubes of 16 inches, and gave the best to Prince Maurice and Archduke Albert, as we shall see below in the testimonies, for which he received money and was asked not to divulge the thing further."

Thus it is very likely that the optical tube held by the archduke in the Extensive Landscape with View of the Castle of Mariemont represents one of these spyglasses belonging to Albert VII as mentioned by Antonini, Bentivoglio, de Rheita and Pierre Borel

We note that the presence of the spyglass in the painting can be used to exclude the year 1608 in the range of the dates for its completion, since the first spyglasses appeared in autumn 1608, while the landscape with the trees and other details in the painting indicates a late summer as the more likely season.

\section{The silver telescopes in the Allegories of Sight}

The Allegory of Sight is one of the five paintings which form the series of the Allegory of the Senses, made by Jan Bruegel the Elder in collaboration with Peter Paul Rubens, which can be admired at the Museum El Prado in Madrid (Belloni 1964).

The painting, oil on wood, is drawn with great accuracy and depicts a hall in the ancient royal Palace of Brussels, residence of the Archdukes, on the hill of Coudemberg, 


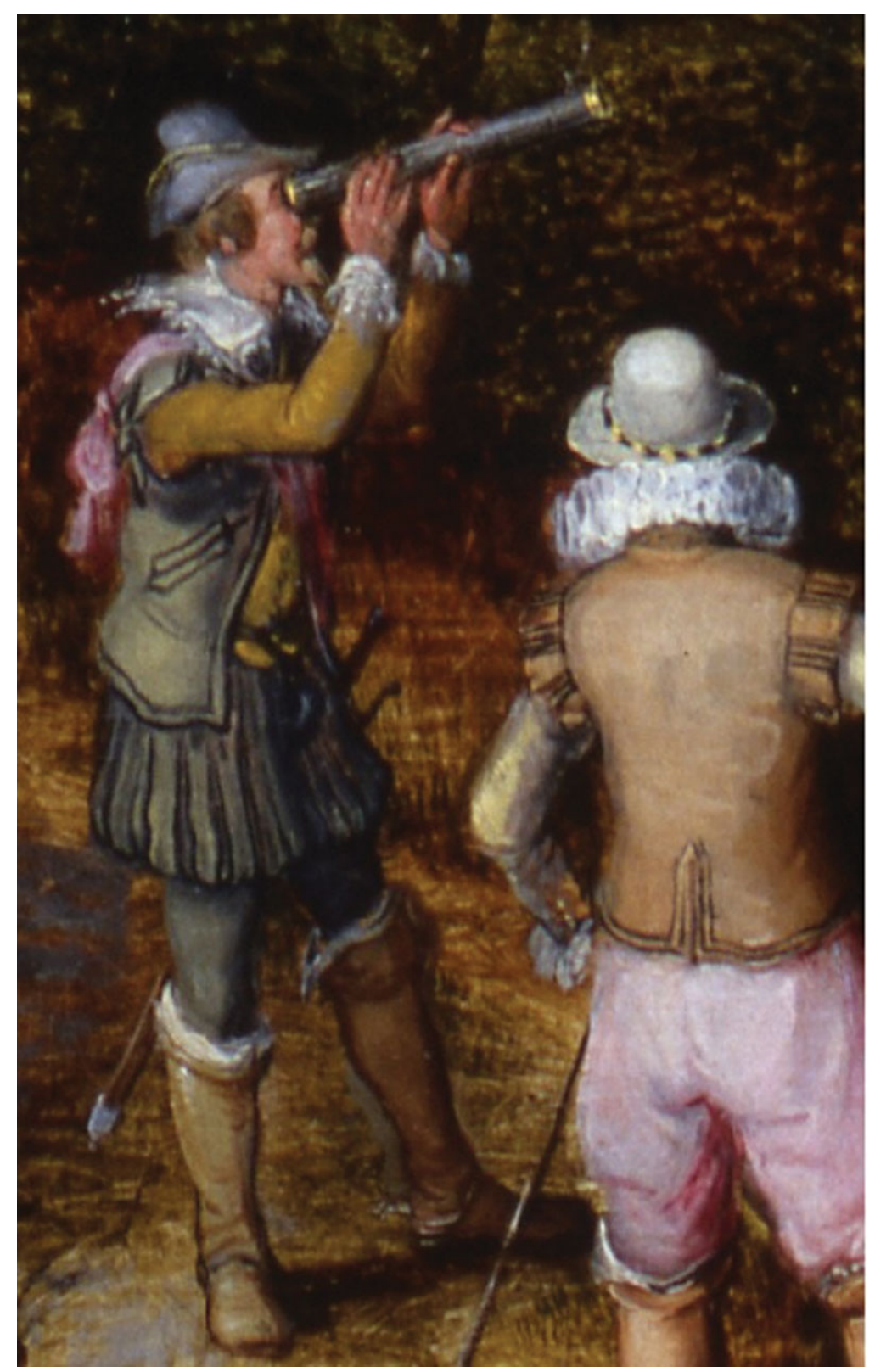

Figure 1. A detail of the painting "Extensive Landscape with View of the Castle of Mariemont" by J. Brueghel the Elder, ca. 1608-1612. Virginia Museum of Fine Arts, Richmond. The Adolph D. and Wilkins C. Williams Fund. Photo: Ron Jennings. The size of the spyglass in the painting is about $3.1 \mathrm{~cm}$.

where their collection of paintings, precious items, and scientific instruments, most of them related to astronomy, were kept. The painting had been completed by 1617 as testified by the date on a roll of several papers lying over a book entitled "Cosmographie", in the lower part of the painting, besides the author's signature. One can note various astronomical instruments such as a large astrolabe, an armillary sphere, a pedestal globe, a pair of Galileian compasses, map dividers and sundials, which testify the 
interest of the Archduke for science, and astronomy in particular. Each instrument has been meticulously characterized with true Flemish skill so that even the minutest details are accurately reproduced.

The telescope between Venus and Cupid (Fig. 2) consists of a main tube and seven draw-tubes, all of which appear to be made of metal, probably silver. Each of the intermediary draw tubes terminates in an enlarged collar that appears to be made of the same metal (Bedini 1971) The lenses are housed in large rounded terminals. The instrument is fixed into a curved metal sleeve support attached to a brass joint which can be adjusted for angle. The pedestrial consists of a turned column terminating in a simpler saucer-shaped round base.

A comparison with other objects depicted in the paintings, indicates a maximum and minimum width for the draw tubes of about 6-7 $\mathrm{cm}$ and $2 \mathrm{~cm}$, respectively, and a total length, if the tubes were all drawn and considering a tilt of about 30 degrees along the line of sight, of about $170-180 \mathrm{~cm}$.

A very similar telescope is reproduced in a larger painting named The Allegory of the Sight and the Sense of Smell, an oil on canvas of considerable size with its 176 for $264 \mathrm{~cm}$. This painting, completed around 1618-1620, was commissioned by the City of Antwerp to J. Brueghel and several other painters to celebrate the visit of the Archdukes to the city. Something about 12 painters, including P.P. Rubens, contributed into the original painting inaugurating the kunstkammer style, that became fashionable afterwards. The painting exposed at the Prado is a copy of the original that was lost in the fire of the Castle of Coudemberg near Bruxelles in 1731. How many painters contributed in the copy that was brought to Madrid in 1623 is still a matter of discussions. However, the discovery of another copy made by a minor painter, Johan Booetz, in 1660 proves that the copy at the Prado is identical to that burned in the fire of the Coudemberg palace. The painting includes several instruments that are identical to those reproduced in the other Allegory of Sight of 1617, however, the two telescopes differ in several details.

The main difference resides in the number of draw tubes: eight against seven, also the rings are colored while they are silvery in the other. Thus, despite the overall similarity in form clearly indicates the same maker, the two telescopes are, apparently, two different instruments.

\section{The monkey's tube}

In the painting of Fig. 2, on the floor, just behind Cupid, and held by a monkey, one can note a tube that "prima facie" looks like an early spy-glass. A close inspection on a high quality reproduction of the painting has instead clearly shown that the tube appears to be made of metal, possibly tin, without any evidence of the above-mentioned supporting structures. The object is clearly a spyglass and its aspect and size clearly indicate that, most likely, it corresponds to the spyglass depicted in Fig. 1. Note that a monkey holding the tube while another monkey is holding two glasses may have allegorical meaning. In Flemish painting the monkey is a traditional symbol for foolishness, and here it may underline the brain-storming implications of the new discoveries or, more simply, the serendipitous way the first telescope had been conceived.

\section{First keplerian telescopes?}

The paintings completion between 1617 and 1618 place a definite upper limit to the date of manufacturing of the instrument therein depicted. Quite remarkable is their technology which appears quite sophisticated for the epoch since there is no record of similar 


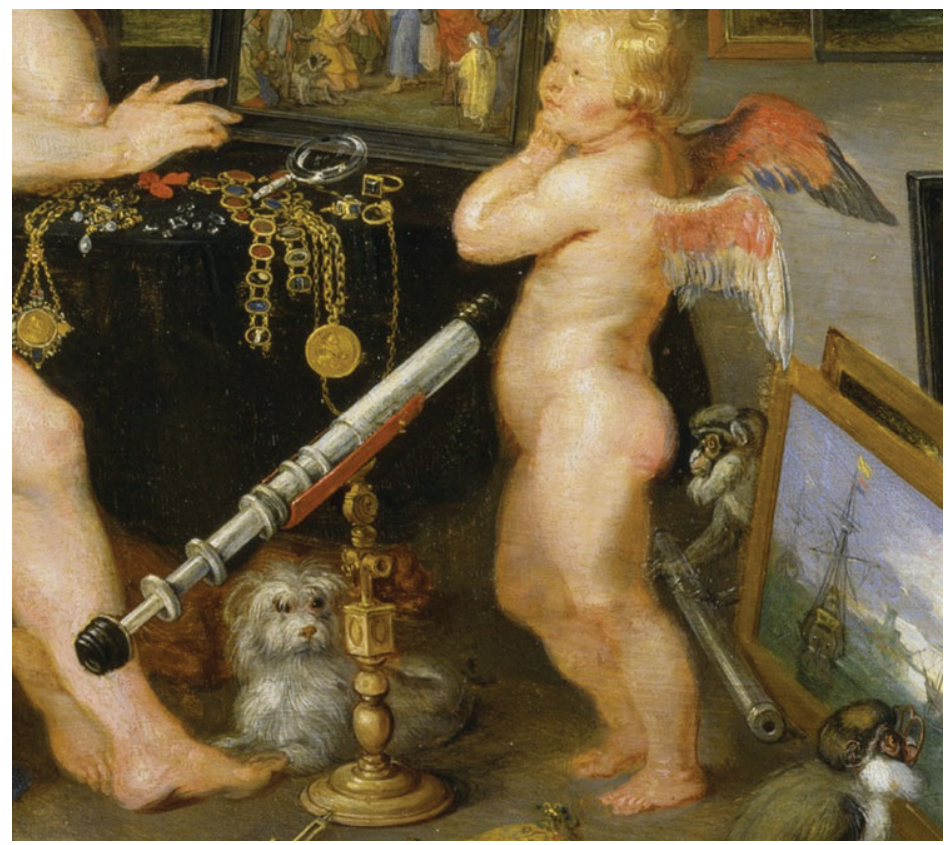

Figure 2. A detail of the painting "The Allegory of Sight" by J. Bruegel and P.P. Rubens, 1617. Madrid, Museo Nacional del Prado. The size of the telescope in the painting is of about 10.3 $\mathrm{cm}$.

instruments earlier than three decades later (cfr the Catalogue of Early Telescopes by Van Helden, 1999). After examining illustrations of early telescopes, the closest resemblance in shape and length is with the illustrations reported in C. Scheiner's works (Disquisitiones Mathematicae 1614, and Rosa Ursina of 1631).

The origin and development of the astronomical telescope, namely the one consisting of two convex lenses, is uncertain and open to question. It was theoretically described by Kepler in his Dioptrice of 1611 but it is not clear when the first astronomical telescope, made by two convex lenses, was manufactured. As a matter of fact Kepler did not make it and we have to wait til the Rosa Ursina completed by Scheiner in 1631 for the first book containing a description of an astronomical telescope. Francesco Fontana in his Novae Celestium Terrestriumque rerum Observationis (1646) claimed to have manufactured an astronomical telescope in 1608 offering also a declaration of father Zupo stating that Fontana had shown a telescope made by two convex lens to him and to father Staserio already in the 1614 .

Three circumstantial considerations seem to support the idea that the instruments depicted in the Allegories may represent the first examples of a keplerian telescope:

- The overall length of the telescope when fully opened is estimated to be about 180 $\mathrm{cm}$. Long telescopes are much easier to make in the keplerian mounting where the two focal lenghts are added. However, with low powers such lenghts would imply a small field of view of few arcminutes which is very unpractical. The small minimal width of the telescope in proximity of the eyepiece is much easy to be obtained with a keplerian mounting rather than with a Doutch munting where the beam never decrease below the size with it reaches the concave length

- The presence of a quite large terminal or eyepiece seems to indicate a compound eyepiece, quite incompatible with a Dutch mounting. In this case, the negative lens needs the eye to be brought as close as possible since the eye's pupil becomes the aperture stop 
and the exit pupil. For the same reason, if the large terminal were just a lens-screen, this configuration would be barely compatible with a Dutch mounting. On the other hand, with a convex lens as eyepiece the eye has to be positioned close to its focus and the structure of the eyepiece is manufactered just to help the eye positioning.

- The first records of Keplerian telescopes are related to the family of the Habsburgs. Cristoph Scheiner in his Rosa Ursina claimed that he made a keplerian instrument in 1614-1617 and showed it to Archduke Maximilian III, brother of Albert VII. In January 4, 1615 Scheiner wrote of a newly invented instrument which actually could be the astronomical telescope, and we note that the date is consistent with the former period as quoted in the later book. According to a different source, in about 1615, Maximilian, received a telescope with two convex lenses and Scheiner added a third one, thus manufacturing a terrestrial keplerian telescope. We note, incidentally, that Scheiner actually used a Dutch telescope for his observations of sunspots in 1611 and it is not clear when he passed to a keplerian one. Certainly not before 1615 as it appears from his manuscript Tractatus de Tubo Optico of 1615 (Daxecker 2001), but more likely only after 1624 (van Helden, 1976) It is quite possible that Albert VII obtained it from Maximilian or heard of it and obtained a similar one for his collection.

\section{Acknowledgements}

We gratefully thank Virginia Museum of Fine Arts, Richmond, the Adolph D. and Wilkins C. Williams Fund. Howell Perkins and Ron Jennings for the high resolution reproduction of the painting. Inge Keil and Franz Daxecker are also thanked for helpful information and valuable discussions.

\section{References}

Bedini, S.A. 1971, Phisis Vol. 13, 149

Belloni, L. 1964, Rendiconti Istituto Lombardo B98, 238

Daxecker, F. 2001, Beiträge zur Astronomiegeschichte, 4, 19

Selvelli, P. 1997, L'Astronomia, 175, 36

Selvelli, P. \& Molaro, P. 2009, in 400 Years of Astronomical Telescopes, B. Brandl, R. Stuik \& J. K. Katgert-Merkelijn (eds) (Berlin: Springer), erratum

Van Helden, A. 1977, Trans. of the Amer. Phil. Soc. 67, part 4

Van Helden, A. 1999, Catalogue of early telescopes (Firenze: Giunti Istituto \& Museo di Storiadella Scienza) 